\title{
CONSIDERACIONES POLÍTICO-CRIMINALES SOBRE EL DELITO DE TRÁFICO DE INFLUENCIAS ${ }^{1}$
}

\author{
María Magdalena Ossandón Widow ${ }^{2}$
}

SUMARIO: 1. Introducción. 2. Conducta tipica y bien juridico protegido. 3. Regulación chilena. 4. Valoración politico-criminal. 5. Interpretación de los tipos a) Influencia con prevalimiento. b) Decisión justa. 6. Conclusiones. Bibliografía.

\section{INTRODUCCIÓN}

El problema de la corrupción se nos presenta, en la actualidad, como una cuestión de primer orden y especial importancia, que preocupa a gobiernos, autoridades y opinión pública en general, tanto en el ámbito nacional como internacional. Ciertamente no podría ser de otra manera, ya no sólo por lo extendidos que se encuentran algunos comportamientos corruptos de funcionarios públicos, por el perjuicio económico que ellos generan para la Administración pública y por la dificultad para controlarlos ${ }^{3}$, sino también por su virtualidad para minar gradualmente los pilares sobre los que se construye el sistema político que nos rige, en cuanto la corrupción constituye, precisamente, una desviación de aquél ${ }^{4}$.

Tradicionalmente el Derecho penal ha constituido uno de los mecanismos de que dispone el Estado para hacer frente a esta preocupante situación, a través de los delitos de prevaricación, cohecho, negociaciones incompatibles, etc. Sin embargo, esta reacción penal no ha parecido suficiente para detener el problema, y es por ello por lo que en las últimas décadas se han agregado nuevas figuras por las que se pretende abarcar otras dimensiones del complejo fenómeno de la corrupción.

\footnotetext{
Trabajo redactado en el marco del Proyecto de Investigación Fondecyt $N^{\circ} 1020657$, "Protección Penal de la fe priblica y de las finciones estatales: estudio dogmátice y crítico", dirigido por el Prof. Luis Rodríguez Collao (Universidad Católica de Valparaíso)

${ }^{2}$ Profesora de Derecho Penal, Universidad Católica de Valpamiso. Doctora en Derecho, Universidad de Navarra

3 "En definitiva, a pesar del principio de división de poderes y del resto de garantías que se prevén en el Estado democrático para el control del poder y la aplicación igualitaria de la ley, se constatan con pesimismo las dificultades con las que se encuentra un control del poder desde el poder y la correspondiente incriminación penal de los funcionarios públicosw, CUGAT MAURI, Miriam, La desviación del interés general y el tráfico de influencias, Cedecs, Barcelona, 1997 , p. 33

${ }^{4}$ Sobre el fenómeno de la corrupción como problemática social-institucional, vid. Cugat Mauri, (n.3), pp. 31-56. El concepto de corrupción sé caracteriza por ser esencialmente relativo a la definición de un determinado modelo politicoinstitucional; "una vez determinado el modelo político, la corrupción se define en función de la desviación de aquél, que puede llegar en los casos más graves, a erigirse en sistema fáctico alternativo al legal. Tal desviación es relevante penalmente cuando afecta la eficacia del modelo. Es decir, existe corrupción cuando los sujetos que tienen atribuida determinada función pública no la realizan y en este sentido dejan inefectivo el modelo, pues de ellos depende el buen funcionamiento del sistema de las instituciones públicas" (p. 50).
} 
Entre todas ellas, quiero destacar ahora el llamado delito de tráfico de influencias, que ha sido incorporado en la legislación de diversos países de nuestro entorno cultural, como, por ejemplo, en España en el año 1991, en Portugal en 1998 y en Argentina en 1999. También Chile se ha unido a esta tendencia en virtud de la ley 19.645 de 11 de diciembre de 1999, que incorpora el artículo 240 bis y un inciso segundo en el artículo 248 bis, disposiciones que hacen referencia al fenómeno en cuestión y por las que se responde al compromiso asumido por nuestro país al suscribir la Convención Interamericana contra la Corrupción (CICC) $)^{5}$.

Ahora bien, sin negar la gravedad del problema que se pretende erradicar, que es innegable cuando se considera el fenómeno de la corrupción en su dimensión global y sistemática, pretendo formular aquí algunas consideraciones político-criminales sobre la verdadera necesidad y conveniencia de que existan tipos especiales para incriminar lo que se conoce como tráfico de influencias. Ellas servirán de fundamento para enjuiciar los tipos concretos que han sido incorporados a nuestra legislación $\mathrm{y}$, al mismo tiempo, permitirán obtener algunas directrices para la interpretación de estas figuras.

\section{CONDUCTA TÍPICA Y BIEN JURÍDICO PROTEGIDO}

Traficar consiste en una actividad de intercambio entre dos partes, cada una de las cuales resulta beneficiada directa o indirectamente. En lo que ahora interesa, el objeto central de este intercambio es una influencia, esto es, la posición de predominio o posición favorable que tiene una persona en relación con determinados centros de decisión ${ }^{6}$, que es ejercida para incidir en el proceso motivador que conduce a un funcionario a adoptar una decisión.

Pero también se suele hablar de tráfico de influencias en un sentido más amplio, que incluye los supuestos en que no se desarrolla esa negociación o intercambio que son propios del tráfico, sino que la conducta involucra el simple ejercicio de influencias de una persona sobre el funcionario habilitado para decidir de un asunto, con el objeto de determinar esa decisión.

En Derecho comparado ambas situaciones han sido modernamente incorporadas como delito en la legislación penal, en regulaciones en que normalmente el tipo central es el que recoge el segundo supuesto, esto es, la conducta del funcionario público que influye sobre otro funcionario, prevaliéndose de alguna situación personal, funcionaria o jerárquica, para conseguir una

\footnotetext{
${ }^{5}$ En la CICC se impone a los Estados la obligación de tipificar o, al menos, considerar la tipificación de ciertas conductas calificadas como corrupción, entre las que figura el tráfico de influencias.

Cfr. Garci^ ARÁN, Mercedes, "Ios delitos de tráfico de influencias en el Código penal de 1995", en MUÑOZ CONDE (dir.), Los delitos contra la Administración Prublica en el nuevo Código penal, Instituto Andaluz de Administración Pública, Sevilla, 1997, ए. 87
} 
resolución que le pueda generar un beneficio económico para sí o para un tercero ${ }^{7}$. En no pocos casos se agrega también la sanción para el particular que ejerce influencias sobre un funcionario público con idéntica finalidad ${ }^{8}$ y en Alemania, incluso, se ha llegado aún más lejos en las propuestas de reforma de la legislación, en que se contempla la sanción de los delitos de tráfico de influencias entre privados. Junto a ellos o de modo independiente, se encuentran también figuras que se refieren al tráfico de influencias en sentido estricto, esto es, al ofrecimiento o negociación que tiene por objeto el empleo abusivo de una posición de influencia.

Al tipificar estas conductas, lo que se pretende, en general, es evitar el ejercicio de presiones sobre la Administración para que adopte determinadas decisiones que resulten económicamente beneficiosas para el interesado". Sea que exista un ofrecimiento y negociación para llegar a ejercer presión, sea que se la ejerza directamente. Como en los demás delitos de funcionarios, el bien jurídico protegido puede definirse en este caso como el correcto funcionamiento de la Administración pública, esto es, la función de prestación a los ciudadanos y el cumplimiento de los criterios objetivos correspondientes a los fines del Estado social y democrático de Derecho. En particular, ello se concreta en los principios de objetividad, imparcialidad y eficacia que informan la actuación de las Administraciones públicas $^{11}$. Para constituir un ilícito penal no bastará, por tanto, con el mero ejercicio de algún modo de presión sobre la Administración pública, presión que en ocasiones incluso puede ser ejercida de manera abierta y por cauces institucionalizados - como ocurre con el derecho a huelga - y por tanto resulta integrada en el sistema ${ }^{11}$. Sino que lo que se quiere evitar, en el fondo, es que la Administración llegue a ser sustituida o reducida a un simple mecanismo de confrontación entre diversos intereses socioeconómicos, desviándose de su función de servicio al interés general, y existiendo además la posibilidad de que se produzca un enriquecimiento espurio e injusto de quienes participan en ella.

Cabe precisar, eso sí, que en el delito de tráfico de influencias no se pretende cautelar el contenido concreto de una decisión, como sucede en los delitos de prevaricación, sino el procedimiento por el que se llega a ella, en cuanto no resulta

\footnotetext{
7 8

nos de este tenor es el art. 428 del Código penal español de 1995, y del art. 432-11 de su similar en Francia.

Elllo se puede verificar a través de un tapo paralelo al del funcionario - en España, el art. 429, y en Francia los arts. 433-1 y 433-2 - o por medio de un único tipo penal de tráfico de influencias de sujeto indiferenciado —así el art. 256 bis del Código penal argentino-.

9ara el caso de conductas que se producen entre particulares, lo que se pretendería proteger es la igualdad, la buena fe en Ios negocios juridicos y la libre competencia.

V. gr, en este sentido, BERdugo GÓMEz DE LA TORRE, Ignacio, "Anotaciones sobre el delito de tráfico de influencias", en OrTS Berenguer (dir), Delitos de los fincionarios priblicos, Consejo Genenal del Poder Judicial, Madrid, 1994, pp. 201-209; CUGAT MAURI, op. cit (n.3), p. 103 y MUNÓz CONDE, Francisco, "Los nuevos delitos de tráfico de influencias, revelación de secretos e informaciones $y$ uso indebido de información privilegiada", Apéndice a Derecho Penal, Parte Especial, 8." ed., Tirant lo Blanch, Valencia, 1991.

11 Cfr. GARriA ARẢN, op. cit. (n. 6), p. 88.
} 
admisible introducir en la motivación del funcionario decisor aspectos ajenos a los intereses públicos, que deben ser los únicos ingredientes de su análisis ${ }^{12}$.

\section{REGULACIÓN CHILENA}

La forma de regulación que se ha adoptado en nuestro país tiene ciertas peculiaridades que la alejan bastante de otros modelos. En la legislación chilena, no se ha sancionado el tráfico de influencias como un delito autónomo, sino que éste se configura únicamente como una modalidad especial de realización de los delitos de negociaciones incompatibles (art. 240 bis) y cohecho (art. 248 bis, inc. $2^{\circ}$ ). En el fondo, se trata de figuras que permiten sancionar una negociación incompatible o un cohecho cuando las estrictas estructuras de imputación del Derecho penal impiden hacerlo. Esto es, cuando el funcionario no reúne los requisitos exigidos al sujeto activo en los respectivos delitos especiales - no es el funcionario encargado de intervenit en la operación en la que se interesa o no es quien debe realizar u omitir el acto de que se trata-, pero se interesa en un determinado contrato u operación y pretende obtener una decisión favorable a sus intereses ejerciendo influencia sobre quien debe decidir, o bien solicita o acepta un beneficio económico para ejercer influencia sobre el funcionario llamado a adoptar la decisión. Conductas que en ciertos casos, y a pesar de revestir un desvalor semejante a las demás, no pueden ser sancionadas directamente a través de las figuras tradicionales.

En el caso del cohecho, en realidad, el ejercicio de influencias puede considerarse constitutivo de una infracción a los deberes del funcionatio, y entonces la conducta podría ser incluida en el tipo básico de cohecho propio del art. 248 bis inc. $1^{\circ}$. Pero la incorporación de un inciso segundo referido específicamente al tráfico de influencias establece una mayor pena para quien solicita o acepta recibir un beneficio económico para sí o un tercero para ejecutar o por haber ejecutado un acto con infracción a los deberes de su cargo, cuando esa infracción consiste, precisamente, en ejercer una influencia sobre otro empleado público con el fin de obtener una decisión que pueda generar un provecho para un tercero interesado. $\mathrm{Y}$ ello, por el mayor potencial dañino y corruptor que estos comportamientos llevan consigo.

Al constituirse como modalidades de las figuras delictivas mencionadas, no cabe duda que el bien jurídico protegido es el mismo que se protege en los respectivos delitos de negociaciones incompatibles y cohecho: la imparcialidad y objetividad en la función pública con la finalidad político-criminal de evitar la desviación del interés general hacia fines particulares ${ }^{13}$.

\footnotetext{
12 "la exclusión de factores subjetivos garantiza las condiciones personales necesarias para la satisfación de los intereses generales objetivizados en la ley y en definitiva pues del principio de igualdad, que está en la raiz de la definición democrática de aquéllos", CugAT Mauri, op, cit. (n.3), p. 104 (destacado en el original).

Cfr., para el caso español, Cugat MAuri, op. cit. (n.3), pp. 104 y ss.; Moral.es Prats/Rodriguez PUerta, "Del tráfico de influencias", en QUINTERo OtIVARES (dir.), Comentarios a la Parte Especial del Derecto penal, $2^{a}$ ed., Aranzadi,
} 


\section{VALORACIÓN POLÍTICO-CRIMINAL}

Volvamos a lo que, en términos generales y amplios, se entiende por tráfico de influencias, para enjuiciar su configuración delictiva desde el punto de vista de su legitimidad y conveniencia político-criminal.

Para ello es necesario establecer si la incriminación de estas conductas cumple con los requisitos mínimos de merecimiento y necesidad de pena y si el Derecho penal es capaz de brindar la función de protección que, en principio, tiene asignada.

En primer lugar y simplificando enormemente el planteamiento, puede decirse que la corrupción, en sus diversas manifestaciones, constituye un grave problema de la sociedad moderna que debe ser afrontado con seriedad y rigor. Como fenómeno general y desde un punto de vista abstracto, por ende, representa un peligro que merecería tutela penal. Sin embargo, dentro de la dinámica y funcionamiento del Derecho penal, que se enfrenta con situaciones concretas para imputar a cada sujeto su conducta particular, la gravedad de cada uno de los comportamientos de corrupción por tráfico de influencias no siempre alcanza una entidad suficiente como para configurar un desvalor penal. Se plantea aquí la problemática de los delitos de acumulación, esto es, de aquellos delitos en que la conducta individual, por sí sola, no es lesiva o peligrosa para el bien jurídico —al menos no en una medida relevante - pero existe la posibilidad cierta de que dicha conducta se realice también por otros sujetos y el conjunto de comportamientos acabe lesionando el bien jurídico. La suma de todos esos comportamientos puede hacer, entonces, que el problema alcance dimensiones alarmantes y que no parezca sólo justificado, sino absolutamente imperioso el recurso a los medios de intervención más severos de que dispone el Estado ${ }^{14}$. No es el momento de detenerme en la consideración de esta problemática, pero baste con advertir que en tales casos la reacción penal resultará siempre desproporcionada respecto del supuesto concreto que se sancione y que, por ende, será ilegitima ${ }^{15}$.

A lo anterior se añade que los delitos de tráfico de influencias se configuran generalmente como delitos de peligro abstracto respecto de un bien jurídico que, de por sí, ya es bastante etéreo y difuso. De este modo, la gravedad de las conductas descritas en el tipo resulta poco contundente y bastante inestable.

Ahora bien, la gravedad global del problema de la corrupción ha sido estimada motivo suficiente por muchos legisladores para justificar la tipificación del

Pamplona, 1999, p. 1269 y MUNOZ CONDE, Limncisco, Derecho penal. Parte especial, $13^{3}$ ed., Tirant lo Blanch, Valencia, 2001, p. 977

14

La punición de los delitos de acumulación ha sido respaldada por importantes penalistas, como por cjemplo, KUHLEN, Lothar, "Umweltstrafrecht - auf der Suche nach einer neuen Dogmatik", en Z.StW" 1993, pp. 715-716, afirma que se trata de arealizar una contribución a la solución de grandes problemas mediante la prohibición bajo amenaza de sanción de acciones, que más bien prestan pequeñas contribuciones a la constitución de estos problemas» (p. 720).

En este sentido Sll va SÁnchez, Jesús Maria, La expansión del Derecho penal, $2^{2}$ ed., Civitas, Madrid, 2001, pp. 132-135. 
tráfico de influencias, apoyados además por la aparente incapacidad de otros mecanismos de control social para prevenir estas conductas. Con todo, este segundo aspecto, el de la necesidad de pena, tampoco parece absolutamente concluyente para legitimar una intervención penal en estos ámbitos. En efecto, en los diversos países en que se ha incorporado a la legislación penal el tipo de tráfico de influencias, la doctrina se ha cuestionado precisamente la necesidad de crear una figura especial para sancionar estas conductas y, en general, se muestra bastante escéptica sobre su verdadera capacidad para prevenir las conductas que se pretenden evitar ${ }^{16}$. Incluso se cuestiona que exista verdadera voluntad política para erradicar estas formas de comportamiento ${ }^{17}$, en tanto que la formulación de estos tipos legales correspondería a un Derecho penal meramente simbólico, que no pretende ser realmente aplicado.

Por el contrario, son otros los mecanismos que, abocados a la misma función, pueden llegar a constituir medios más idóneos y eficaces para combatir el tráfico de influencias intentando, fundamentalmente, eliminar sus cauces. Como afirma BERDUGO GÓMEZ DE LA TORRE, «para atacar las raíces profundas de los comportamientos que se quieren evitar, hay que acudir al empleo de otros instrumentos distintos del Derecho penal, como puede ser la normativa de incompatibilidades, una eficaz inspección o el control parlamentario» ${ }^{18}$. En efecto, en estos ámbitos parece mucho más efectivo reforzar la regulación preventiva en el propio seno de la actividad política y administrativa en que se desarrollan las conductas que se pretenden evitar. Asi, mejores resultados pueden obtenerse si se acentúa la importancia de la responsabilidad politica de los funcionarios, si se regula y se independiza de la contingencia política —en la medida en que ello sea posibleel tema de las comisiones de investigación, si se clarifica y ordena la legislación administrativa sobre los funcionarios públicos, sus competencias y la transparencia en sus actividades, si se delimita mejor el ámbito de la discrecionalidad, cerrando los espacios legales que permiten la arbitrariedad, etc. ${ }^{19}$

Asimismo, la sanción de las conductas de tráfico de influencias desde el propio Derecho administrativo ha de ser un mecanismo de control previo al del Derecho penal. En nuestro país, por ejemplo, la Ley de Bases Generales de la

\footnotetext{
${ }^{16}$ En general, para el caso español, vid. DiAZ Y GARCiA CONLledo, Miguel, "El delito de tráfico de influencias", en AsuA BATArrita (ed.), Delitas contra la Administración Püblica, IVAP, Bilbao, 1997, p. 177; GARCiA ARÁN, op. cit. (n. Ø), pp. 8990 y SuArEZ MONTlS, Rodrigo, "Consideraciones politico-criminales sobre el delito de tráfico de influencias", en Politica Criminal y Reforma Penal. Homenaje a la memoria del Prof. Dr. D. Juan del Rosal, EDR, Madrid, 1993, p. 1091.

En particular sobre cl tema de la justificación de la necesidad de regulación autónoma del delito de tráfico de influencias, CUgat MAUri, op. cit. (n.3), pp. 131-166.

17 Asi Berdugu Gómez de LA TORRE, op, cit. (n. 17), p. 205 y SUÁriz Montes, op, cit. (n. 16), p. 1091.

${ }^{18}$ BERDUGO GÓMEZ DE LA TORRE, op. cit. (n. 17), p. 206.

En este sentido GArCiı Arín, op cit. (n. 6), p.103, y especialmente, SuÁrEZ. MONTES, op. cit. (n. 16), pp. 1092-1094 y 1105, quien sugiere delimitar los ámbitos de la discrecionalidad para así dotar al delito de prevaricación y congéneres del soporte normativo necesario para su operatividad.
} 
Administración del Estado prohibe, como conducta reñida con el principio de probidad, «hacer valer indebidamente la posición funcionaria para influir sobre una persona con el objeto de conseguir un beneficio directo o indirecto para sí o para un tercero ${ }^{20}$. Como la norma no distingue, la persona sobre la que se ejerce influencia puede ser tanto un particular como otro funcionario.

Entonces, el recurso al Derecho penal sólo estaría justificado en los supuestos especialmente graves en que, además, el Derecho administrativo se hubiese mostrado incapaz de producir los efectos esperados. Para dilucidar esta última cuestión es preciso determinar si la norma administrativa se aplica eficazmente, y, en caso de no ser asi, establecer las causas que lo impiden. Cuando la norma sancionadora administrativa no resulte ni siquiera aplicable, por ejemplo, por dificultades probatorias, procesales, etc., resultaría bastante ingenuo esperar mejores resultados a través de un ordenamiento más formalista y exigente como es el Derecho penal.

En este sentido, cabe destacar el ánimo que ha llevado a dictar la Ley sobre Probidad Administrativa ${ }^{21}$, que modifica la regulación de Derecho administrativo en la materia, y la potencialidad que ésta ofrece si es aplicada con sentido común y buen espíritu. En la práctica, para afrontar el problema de la corrupción, una opción como ésta parece más sincera - en cuanto a la voluntad política de erradicar el problema-y más útil - como medida de prevención-que el recurso a la intervención penal.

Centrando el examen ahora en el interior de la legislación penal, se puede advertir que el Derecho penal ya contaba con algunos mecanismos para hacer frente al problema. Fundamentalmente a través de los tipos sobre cohecho, prevaricación y negociaciones incompatibles, en los que suelen derivar las situaciones más graves de corrupción por tráfico de influencias.

Advierte GARCíA ARíN ${ }^{22}$ que los tipos de cobecho recogen situaciones en las que genéricamente interviene un sujeto con cierta posición de predominio por su condición de funcionario con competencia en determinadas materias, y un particular que busca la ventaja que puede proporcionar esa posición, produciéndose entre ambos un ofrecimiento o solicitud de intercambio con contenido económico. Por otra parte, los tipos de prevaricación admiten, según una extendida opinión doctrinal, la participación como inductor del particular o de cualquier funcionario que no sea el competente para actuar y que pretende obtener la decisión manifiestamente injusta. $Y$, por último, el vasto ámbito de sujetos a quienes dar interés constituye un delito de negociaciones incompatibles permite incluir en esa figura

\footnotetext{
20

Art. 62.2 del DFL n ${ }^{\circ} 1 / 19.653$, publicado en el Diario Oficial de 17 de noviembre de 2001, que fija el texto refundido, coordinado y sistemático de la Ley 18.575 Orgánico Constitucional de Bases Generales de la Administración del Estado.

Ley 19.653, publicada en el D.O. del 14 de diciembre de 1999, que agrega un Titulo III a la ley 18.575 de Bases Generales de la Administración del listado.

22

GARCiA ARÁN, op. cit. (n. 6), pp. 89 y 90 .
} 
muchas de las conductas corruptas de los funcionarios que deben intervenir de algún modo en el negocio u operación y que, al hacerlo, favorecen a algunos de esos sujetos. En caso de que estos últimos hubiesen logrado que se les diera ese interés ejerciendo sobre el funcionario la influencia que les concede su relación de parentesco, su vínculo empresarial, etc., eventualmente también podrían ser sancionados como inductores del delito cometido.

En todo caso, es evidente que quedan todavía supuestos no regulados, que no se pueden incluir en los anteriores delitos. Así, el cohecho no comprende los casos en que no se ofrece claramente una contraprestación económica para obtener una actuación administrativa. Tampoco constituyen delito de prevaricación los supuestos en que la decisión que se pretende obtener no es manifiestamente injusta, pese a que no deje de ser irregular. Las negociaciones incompatibles sólo se configuran cuando se da interés a una de las personas expresamente contempladas en la norma y que se vinculan de algún modo con el empleado que debe intervenir en el contrato u operación, de lo contrario, la conducta sería atípica, responda o no al ejercicio de una determinada influencia sobre el órgano decisor. $\mathrm{Y}$, en general, además de los límites que impone el principio de accesoriedad para la sanción de los partícipes ${ }^{23}$, no deja de resultar controvertida la posibilidad de sancionar al extraneus - quien no cumple con los requisitos exigidos para el sujeto activo del delito, sea particular o funcionario-como partícipe en el delito cometido.

Pese a lo anterior, cabe recordar que el Derecho penal es y ha de ser necesariamente fragmentario, pues le corresponde sólo una parte de la función general protectora de bienes jurídicos: no protege todos los bienes jurídicos sino nada más que los fundamentales, y sólo frente a los ataques más intolerables que puedan amenazarles. Esta característica no constituye un defecto de esta rama del ordenamiento jurídico, tal como inicialmente fuera concebida por BINDING, sino que representa una exigencia del Estado de Derecho y uno de los principios garantísticos que la informan.

Finalmente, hay que destacar que la elaboración de un tipo que abarque todos los supuestos en que se efectúe un ejercicio de influencias ilegítimo y reprobable es necesariamente difícil y difusa ${ }^{24}$, pues «se trata de situaciones

\footnotetext{
23

La autonomía del delito de tráfico de influencias respecto del de prevaricación tiene al menos el buen efecto de que hace viable la exigencia de responsabilidad penal a quien ha influido a un acto verdaderamente corrupto, pero que no constituye prevaricación para el funcionario por obrar al amparo del arbitrio legal, cfr. SUÁREZ MONTES, op. cit. (n. 16), p. 1096. Del mismo modo, su punición facilita que el funcionario que es objeto del ejercicio de influencias denuncie la conducta, pues el delito generalmente se entiende consumado por el mero hecho de ejercer presión, sin requerir que se haya obtenido el resultado perseguido por el autor, es decir, sin esperar a que el funcionario influido adopte la decisión que se le exige.

${ }^{24}$ Sirve de ejemplo la descripción que se formula en la CICC, art. XI c, en que se propone sancionar: "toda acción u omisión efectuada por cualquier persona que, por sí misma o por persona interpuesta o actuando como intermediaria, procure la adopción, por parte de la autondad pública, de una decisión en virtud de la cual obtenga ilicitamente para sío para otra persona, cualquier beneficio o provecho, haya o no detrimento del patrimonio del Estado". La conducta resulta absolutamente indeterminada, pues consiste en toda — cualquier- acción u omisión que sirva para procurar la adopción de una decisión.
} 
considerablemente resbaladizas y difíciles de precisar en una redacción legabs ${ }^{25}$. En consecuencia, se hace prácticamente incompatible satisfacer, al mismo tiempo, las exigencias del principio de legalidad —en cuanto a la determinación de la ley penal- y los requisitos de efectividad en la protección del bien jurídico que se pretende amparar. La tendencia general es, lamentablemente, resolver el conflicto dando primacia a esto último, con lo que se multiplica la elaboración tipos considerablemente indeterminados.

En definitiva, la configuración de un tipo autónomo que sancione el tráfico de influencias, en general, no cumple satisfactoriamente con el requisito de merecimiento de pena, ni resulta del todo evidente la necesidad de contemplar expresamente estas conductas en un tipo, figura que resulta residual respecto de otros delitos y que, por ende, posee un reducido ámbito de aplicación.

Desde el punto de vista aquí asumido, por tanto, la fórmula empleada por nuestro legislador para sancionar algunos supuestos de tráfico de influencias resulta más adecuada que su configuración como delito autónomo. Ello, en tanto en cuanto restringe la incriminación de estas conductas a algunos de los supuestos de mayor gravedad, vinculados con los delitos de negociaciones incompatibles y cohecho $^{26}$. Supuestos en que se aprecia, al menos, un ilícito de entidad similar al contemplado en la configuración original de esos respectivos delitos, pero que no resultaba sancionable en la medida en que el sujeto activo no reunía las cualidades necesarias en ellos exigidas ${ }^{27}$.

\section{INTERPRETACIÓN DE LOS TIPOS}

Más allá de las observaciones de política-criminal que puedan efectuarse sobre el delito de tráfico de influencias, una vez que la figura ha sido incluida en la legislación el análisis no puede limitarse a la crítica sobre su oportunidad y conveniencia, sino que es preciso intentar dar respuesta a los problemas interpretativos a que puede dar lugar. En esta tarea, es necesario considerar tanto la finalidad de la norma como el respeto a los principios garantísticos propios del Derecho penal, en un análisis funcional de las figuras, siempre abierto a las consideraciones político-criminales que están de fondo.

\footnotetext{
${ }^{25}$ Garcia ARÁn, op. cit. (n. 6), p. 90.

26

En este sentido, DínZ y GARCí CONLLEDO, op, cit. (n. 16), p. 178 estima que, en España, habria sido mejor tipificar los casos más graves de tráfico de influencias por la via de la inclusión de alguna previsión al respecto dentro de los delitos de cohecho.

27

En todo caso, siempre puede discutirse la legitimidad del tipo que sanciona las negociaciones incompatibles, conducta que en otras legislaciones es sancionada en casos más específicos (España) o es atipica salvo que pueda ser reconducida hacia otras figuras (Francia e Italia). Pero ello nos trasladaría a un nivel de análisis diverso, que no es posible asumir en este espacio.
} 
Esta perspectiva conduce a proponer, en líneas generales, una interpretación restrictiva de los tipos incorporados en nuestro Código penal ${ }^{28}$. En concreto, ello se manifiesta en dos cuestiones que pasaré a examinar: en primer lugar, en la exigencia de que el agente ejerza su influencia prevaliéndose de alguna circunstancia especial de superioridad o predominio; y, en segundo lugar, en orden a excluir del ámbito típico los supuestos de ejercicio de influencia para obtener una resolución justa.

\section{a) Influencia con prevalimiento}

En el ámbito penal la expresión influir se ha entendido como kincidir en el proceso motivador que conduce a un funcionario o autoridad a adoptar una decisión en un asunto relativo a su cargo" ${ }^{29}$. Sin embargo, esto no significa que el tipo de tráfico de influencias se constituya con la simple influencia sin más. No resulta apropiado ni legítimo penalizar la mera recomendación o sugerencia, pues se trata de una práctica, bastante habitual por lo demás, que aunque sea inmoral y rechazable, no afecta directamente o no tiene por qué afectar a la decisión que se adopte ${ }^{30}$.

Se requiere, para configurar la conducta típica, el ejercicio de «una mayor presión sobre la voluntad del funcionario, de manera que se afecte en cierta medida la libertad en la formación de esa voluntad ( $\sin$ que sea necesaria una anulación de la misma ni una fuerte coacción sobre ella)» ${ }^{31}$. Por lo demás, esta exigencia se condice con el significado normal del término, pues según el Diccionario de la Real Academia española influir consiste en «ejercer una persona o cosa predominio o fuerza morals.

Éste es considerado un requisito esencial del tipo en cuanto, precisamente, constituye el elemento que individualiza a esta conducta como punible respecto del mero ejercicio de influencias, que resulta impune ${ }^{32}$. En otras palabras, la acción se delimita mediante un medio determinado: el ejercicio de influencias sólo adquiere

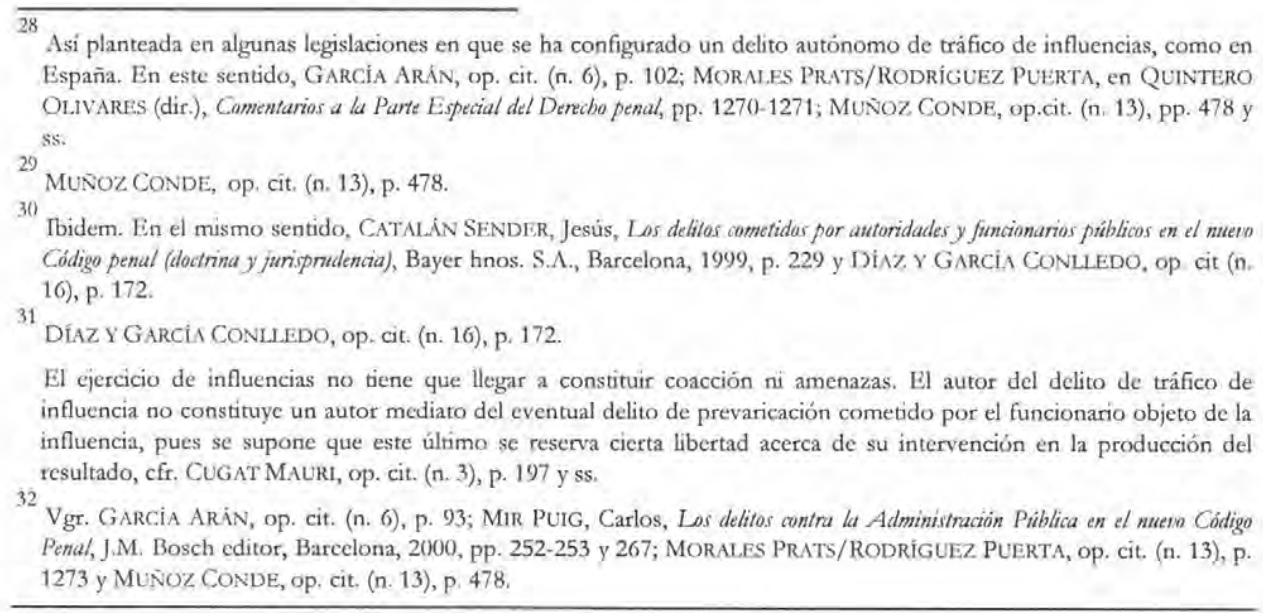


relevancia penal cuando se hace uso del prevalimiento o abuso ${ }^{33}$, que constituye un factor de incremento del riesgo de desviación de la función pública ${ }^{34}$. Normalmente es un requisito que se deriva sin mayores inconvenientes de la mención expresa que los tipos de tráfico de influencias suelen hacer a que se actúe con prevalimiento o abuso.

Los artículos 428 y 429 del Código penal español se refieren a una actuación prevaliéndose del ejercicio del cargo o de una situación derivada de la relación personal o jerárquica con el funcionario público sobre quien se ejerce la influencia o con otro funcionario o autoridad; el art. 335 del Código penal portugués y los artículos 432-11 y 433-1 de su similar francés aluden a que se abuse de una influencia real o supuesta.

El proyecto original de reforma de nuestro Código penal también hacía referencia a que el autor influyere prevaliéndose de su cargo (delito cometido por un empleado público, art. 259 bis) o de cualquier situación de preeminencia en la sociedad, sea de carácter político, económico, gremial, sindical o de otra naturaleza, o de sus relaciones de parentesco o amistad (delito cometido por un particular, art. 259 bis A). Sin embargo, la excesiva amplitud de la descripción de esas situaciones de prevalimiento diluían, en parte, esta exigencia, y en el caso de ofrecimiento de uso de influencias (art. 259 bis B) no se contemplaba ningún requisito de esta naturaleza.

Ahora bien, la redacción definitiva de las figuras incorporadas en nuestro Código penal por la ley 19.645 que hacen referencia al ejercicio de influencias - los arts. 240 bis y 248 bis inc. $2^{\circ}$ - no contienen ninguna precisión sobre la forma en que ha de materializarse esta conducta. Más aún, en ambos supuestos, el sujeto activo del delito ha de ser funcionario público pero, a diferencia de lo que suele ocurrir en los delitos de este Título, éste puede ser cualquiera. No se le exige competencia especial ni superioridad respecto del funcionario objeto de las influencias.

Pese a ello, entiendo que los tipos deben interpretarse en un sentido restrictivo en este punto, circunscribiendo la relevancia típica de la conducta a los supuestos en que el funcionario público ha ejercido una influencia aprovechándose o prevaliéndose de su función, de su relación jerárquica o de su relación personal con el empleado que debe adoptar la decisión. Esta circunstancia, que le confiere un cierto predominio sobre el empleado objeto de influencia, ha de considerarse como el medio idóneo que utiliza el autor para lograr su objetivo. Si no existe

\footnotetext{
33

El pretulimiento es definido como la «utilización, por parte del funcionario o autoridad, de una determinada situación de poder - que puede derivar tanto del cargo que ostenta como de cualquier otra circunstancia personal- como mero instrumento que permite, con mayor facilidad, cl condicionamiento de la decisión que, en el marco de la gestión pública, debe adoptar otro funcionariom, MOrilias Cueva/Portul. A CONTRERAS, "Los delitos de revelación de secretos, uso de información privilegiada, cohecho impropio y tráfico de influencias", en COBO DEI. ROSAL. (dir.), Comentarios a la Legislación penal, XVI, EDR, Madrid, 1994, pp. 232-233.

34

Asi, y en relación con la criminalidad organizada, CUGAT MAURI, op. cit. (n. 3), pp. 200-204.
} 
alguna forma de prevalimiento la conducta podría ser calificada como una mera recomendación o sugerencia, que no tendría entidad suficiente para ser incluida en el ámbito típico.

Las consideraciones de política-criminal antes expuestas conducen a esta conclusión, pues la conducta tiene que expresar un especial desvalor - un desvalor jurídico-penal - para ser objeto de una sanción de esta clase. Pero cabe precisar un poco más los argumentos que avalan esta posición.

Por una parte, como ya he expuesto, el sentido natural del término puede interpretarse de este modo. Los actos que realice el sujeto activo deben tener la suficiente idoneidad como para incidir y alterar el proceso motivador del empleado que debe adoptar una decisión.

Más aún, en España GARCí ARÁN plantea que el término influir podría considerarse como inclusivo de un cierto resultado, entendido como el efecto de la influencia objetivizado en una conducta desviada del sujeto pasivo: influir podría entenderse como consecución de un cambio de actitud o determinación de un comportamiento en el sujeto influido. Sería exigible entonces que el presionado se comportara de acuerdo con las pretensiones del sujeto activo y, por tanto, entender que la consumación exige la resolución como resultado. Sin embargo, la autora reconoce que la utilización del término para en la descripción típica - «el que influyere.., para conseguir...»—, hace difícil aceptar esta interpretación ${ }^{35}$.

En cuanto a la exigencia de una especial gravedad de la conducta, es verdad que en el caso chileno, al enmarcarse ésta en el ámbito de los delitos de negociaciones incompatibles y de cohecho, puede ser objeto de un mayor juicío de desvalor. Porque en el primer caso se trata de ejercer influencias con una finalidad desviada, cual es la de interesarse o dar interés en un contrato u operación en la que debe intervenir otro empleado público; y en el segundo, es la motivación de la conducta la que aparece especialmente viciada, pues se ha generado por la solicitud o aceptación de un beneficio económico. Con todo, la posibilidad de sancionar penalmente un comportamiento aunque no se trate del funcionario encargado de intervenir en el contrato u operación, en el supuesto de negociaciones incompatibles, o la mayor pena con que se amenaza la infracción al deber del cargo que consiste en ejercer influencias, en el del cohecho, deben estar justificadas en sí mismas por su especial gravedad. De lo contrario, sólo se podrían castigar de conformidad con el tipo general de cohecho o con la respectiva normativa de carácter administrativo.

En cuanto a esto último, no está de más recordar que incluso la legislación administrativa, cuando prohibe la realización de ciertas conductas como reñidas con el principio de probidad, se refiere a «hacer valer indebidamente la posición funcionaria para influir sobre una persona con el objeto de conseguir un beneficio

\footnotetext{
${ }^{35}$ Gareín ARin, op cit. (n. 6), p. 95.
} 
directo o indirecto para sí o para un tercero» (art. 62.2 Ley de Bases Generales de la Administración del Estado). Es decir, se pone el acento en que la presión o influencia que se ejerce sea indebida, con lo que, además de excluir del ámbito infraccional los supuestos que están dentro del campo de las atribuciones o competencias del funcionario, se confiere al comportamiento una mayor carga negativa.

A los anteriores argumentos, que todavía no pueden estimarse del todo concluyentes, es preciso añadir el de la interpretación sistemática de las figuras respectivas. Tanto en el caso de negociaciones incompatibles como en el supuesto agravado de cohecho, se trata de delitos de mera actividad en que basta que el sujeto persiga subjetivamente su objetivo para que se entienda consumada la figura. Se les puede calificar también como delitos de resultado cortado, en cuanto la intención del autor al ejecutar la acción típica debe dirigirse a un resultado independiente de él, resultado que, sin embargo, no es preciso que llegue a producirse realmente ${ }^{36}$. En este sentido, la estructura de estos delitos es muy próxima a la de los supuestos de participación; tanto, que se ha entendido que el tráfico de influencias constituye un caso especial de inducción elevado a la calidad de autoría $^{37}$. Sin embargo, son modalidades que se configuran como tipos independientes, con sus propias reglas de imputación diferentes a los supuestos generales de inducción. Así, por ejemplo, no se requiere que la conducta sea eficaz en cuanto al resultado, es decir, que el autor consiga que el empleado sobre quien se influye adopte la decisión perseguida - por eso constituyen delitos de mera actividad- lo que sí se exige para que la inducción resulte punible ${ }^{38}$. Aunque eso no implica que, como aquí he defendido, deba tratarse siempre de una influencia directa, real y suficiente, es decir, dotada de la capacidad objetiva de mover al funcionario a dictar la resolución ${ }^{3 !}$.

Pero lo que quiero destacar es que el delito de tráfico de influencias incluso cuando aparece asociado con los delitos de negociaciones incompatibles y cohecho- está íntimamente relacionado con la figura de indución a la prevaricación. En ambos casos se sanciona la conducta de quien no es el funcionario que adopta la decisión injusta o desviada, si bien la estructura de imputación es algo diferente y, además, la de los delitos que estamos analizando revela un mayor desvalor de la conducta, pues al ser cometida por un funcionario público atenta directamente contra sus deberes de probidad y afecta el correcto funcionamiento de la Administración pública.

\footnotetext{
${ }^{36}$ Cfr. Cugat Mauri, op. cit. (n. 3), p. 231; y Mir Puig, op, cit (n. 32), p. 264.

37 En este sentido CATAl.án SENDer, op. cit. (n. 30), p. 229 y Cugat MAUri, op. Cit. (n. 3), p. 192.

${ }^{38}$ CUgat Mauri, op. cit. (n. 3), pp. 191-195.

39 Asi, Diazy Garcia CONLledo, op. cit. (n. 16), p. 173 y Garcia Arin, op. cit. (n. 6), p. 98.
} 
La penalidad aplicable al inductor en el delito de prevaricación administrativa (art. 228) es de suspensión del empleo en su grado medio y multa de 11 a 15 UTM; en tanto que quien comete el delito tipificado en el art. 240 bis puede ser sancionado con las penas de reclusión menor en su grado medio, inhabilitación especial perpetua para el cargo u oficio (que también puede llegar a ser inhabilitación absoluta perpetua para cargos u oficios públicos) y multa del $10 \mathrm{al}$ $50 \%$ del valor del interés que hubiere tomado en el negocio; y el autor de cohecho con tráfico de influencias puede ser sancionado con reclusión menor en su grado mínimo a medio, inhabilitación especial o absoluta para cargo u oficio público perpetuas y multa del tanto al duplo del provecho solicitado o aceptado. La gravedad de las penas con que se sanciona estos supuestos de tráfico de influencias viene determinada, fundamentalmente, por la penalidad con que se amenaza la comisión de los delitos con que se les vincula ${ }^{40}$. Pero eso mismo ha de conducir a exigir que la influencia ejercida sea de una magnitud tal que pueda asimilarse, cuanto menos, a la inducción a esos delitos, esto es, que sirva para determinar al otro a cometer el hecho.

En todo caso, el modo en que se ejerce la influencia no requiere llegar a configurarse como una especie de coacción o amenazas, ni el delito se constituye como una figura de autoría mediata ${ }^{41}$.

Si efectivamente la conducta puede calificarse como amenazas — tipificadas en los arts. 296 y 297 del Código penal- estaríamos frente a un concurso ideal de delitos. Entiendo que no puede considerarse como un concurso aparente de leyes penales porque el tráfico de influencias no ha considerado el mayor desvalor de una amenaza, sino que se conforma con una influencia ejercida con prevalimiento de una determinada circunstancia o relación, y, a su vez, el delito de amenazas no contempla la lesión a la función pública propia del tipo de tráfico de influencias.

Por último, siempre se puede interpretar la exigencia de prevalimiento como requisito del tipo en virtud de los principios de insignificancia o adecuación social, para completar la relativa indefinición de las descripciones típicas a este respecto. La mera sugerencia o recomendación para que se adopte una determinada decisión constituyen comportamientos absolutamente habituales en nuestro sistema y propios de nuestra idiosincrasia, que aunque sean reprochables desde muchos puntos de vista, no aparecen provistos de una nocividad social que justifique la intervención penal.

\footnotetext{
411 En este sentido también puede estimarse adecuada la forma en que se configuran los ilícitos en nuestro Código Penal, porque da valonción juridica del hecho de influir en otro para que lleva a cabo un determinado acto, debe hacerse tomando como punto de referencia el acto a cuya ejecución se induce o instiga. La clase y naturaleza del acto en que se participa es determinante», SUÁREZ MONTES, op. cit, (n. 16), p. 1094.

11 En extenso, CUGAT MAURI, op. cit. (n. 3), pp. 197 y ss.
} 


\section{b) Decisión justa}

El delito de tráfico de influencias se comete cuando un funcionario ejerce su predominio sobre otro para obtener de éste una decisión favorable a sus intereses o a los intereses de las personas individualizadas en la norma (art. 240 bis), o una decisión que pueda generar un provecho para un tercero interesado (art. 248 bis). Las disposiciones en cuestión no precisan nada más acerca de la adecuación o legalidad de esa decisión, que podría admitir un triple carácter: a) decisión adecuada a Derecho (legal), b) decisión no adecuada a Derecho pero no prevaricadora, y c) decisión prevaricadora o manifiestamente injusta.

En este último caso, de una resolución manifiestamente injusta, es indudable que se cumplen los requisitos del tipo. Más aún, puede advertirse que se produce aquí un concurso con el delito de inducción a la prevaricación. Aparentemente, la figura de tráfico de influencias - tal como está sancionada en nuestra legislaciónprevalecería sobre la anterior por su mayor gravedad y especificidad. Sin embargo, parece más correcto establecer un concurso ideal entre ambos delitos, por tratarse de una sola acción que no queda comprendida totalmente en uno de los tipos (el tráfico de influencias no comprende el desvalor de la injusticia de la resolución) ${ }^{42}$.

Cuando la decisión que adopta el empleado sobre quien se ejerce la influencia es ilegal pero no alcanza para configurar el delito de prevaricación, quedaría de todos modos consumado el delito de negociaciones incompatibles o cohecho con tráfico de influencias si se cumplen los demás requisitos de las figuras pertinentes. Es conveniente incluir estos supuestos en el ámbito típico, porque restringir el delito de tráfico de influencias sólo a la provocación de resoluciones claramente prevaricadoras supondría restar eficacia a estos nuevos delitos de una forma muy considerable, puesto que únicamente se consideran como prevaricadoras las decisiones abiertamente desviadas o arbitrarias. Cuando existen ilegalidades de poca relevancia o desviaciones procedimentales, el recurso a la prevaricación puede considerarse ciertamente exagerado por lo leve de la infracción, pero no así la punición de la presión ejercida sobre el funcionario para que altere el funcionamiento de la Administración ${ }^{43}$. En suma, considerando que se quiere proteger la objetividad e imparcialidad de la Administración, cabe concluir que los tipos comprenden, también, la influencia dirigida a la realización de un hecho penalmente atípico, pero desvalorado.

Pero el supuesto más problemático se produce cuando se ha ejercido una influencia para que se adopte una decisión que es material y formalmente adecuada a Derecho. Es verdad que en estos casos existe un funcionamiento anómalo y se atenta contra la pureza de los actos de la Administración, pero ¿jes esto suficiente

\footnotetext{
42

Asi MiR PUIG, op. cit. (n. 32), p. 259

${ }^{43}$ Cfr. GarCi A ARÁN, op. cit. (n. G), p. 96
} 
para configurar el ilícito específico de que se trata? Hay que considerar que a través del tipo de tráfico de influencias, incluso cuando se sanciona de modo autónomo, no se pretende, sin más, resguardar el procedimiento, la pureza de la Administración y la probidad de sus funcionarios. Si asi fuera, el ejercicio de influencias debería sancionarse en todos los supuestos en que ella se produce. Pero el legislador penal conmina esta conducta sólo en casos específicos, cuando se realiza para obtener una resolución que implique un beneficio económico ${ }^{44}$. Por ende, no se puede afirmar que la sola forma como se arranca la resolución sea motivo suficiente para sancionar, por atentar contra la pureza de los actos de la Administración, porque entonces ello sería punible siempre, con independencia de que la resolución implique un beneficio económico para el interesado.

Sin embargo, tal como afirma SUÁREZ MONTES, «el beneficio económico fruto de un acto administrativo materialmente procedente, no debe ser estigmatizado por el Derecho penal». La obtención de ese beneficio no es de suyo malo, aunque en muchos casos proceda la sanción de las conductas que lo permiten. Pero lo cierto es que «no parece admisible una responsabilidad penal por inducción a un acto que desde la vertiente del funcionario no constituye prevaricación o alguna otra infraccións ${ }^{45}$. Esto es, cuando la decisión del funcionario ha sido adoptada, de todos modos, con una aplicación estricta de los criterios técnicos pertinentes.

Por otro lado, para que se realice la parte objetiva del tipo es también necesaria la denominada imputación objetiva de la conducta al resultado típico, esto es, que exista una relación de riesgo - entendida como categoría normativa-, de modo que la conducta cree un riesgo típicamente relevante que se realice en el resultado, considerando como criterio para su determinación el fin de protección de la norma. Desde este punto de vista, cuando lo que se pretende es obtener una resolución justa, la acción típica de influir con prevalimiento en otro funcionario no crea un riesgo típicamente relevante o intolerable pues no afecta el buen funcionamiento y la objetividad e imparcialidad del actuar administrativo, o lo afecta sólo de un modo insignificante ${ }^{46}$.

De este modo, sería penalmente impune el supuesto del funcionario que influyera con prevalimiento de su cargo o de su relación personal sobre otro indicándole a quien debe elegir entre varios candidatos, siempre que ese candidato reúna todos los requisitos exigidos y aun cuando ello signifique que el elegido se verá económicamente favorecido.

Más evidente aún sería el supuesto en que un abogado tiene noticia de que su cliente va a ser discriminado injustamente y presiona sobre el Magistrado

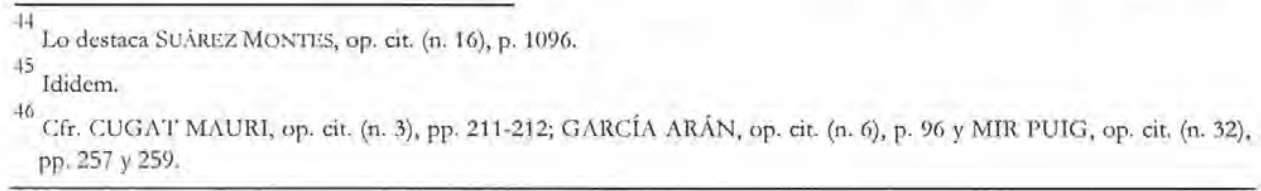


prevaliéndose de su relación de amistad con el mismo. En cuanto la conducta tiene por objeto que se respete la legalidad, no puede ser constitutiva de ilícito penal.

Ahora bien, en la medida en que nuestra legislación asocia el ejercicio de influencias a los delitos de negociaciones incompatibles y cohecho puede parecer que las circunstancias que rodean el acto son suficientes para configurar un ilícito penal. Así, tal como en la figura de negociaciones incompatibles el mero interesarse es delito, aquí puede decirse que existe un interés indirecto, pero la imparcialidad y pureza de la Administración resultaría igualmente afectada ${ }^{47}$. Sin embargo, el interés porque la actuación de los funcionarios esté permanentemente libre de sospecha, con ser absolutamente legítimo, resulta demasiado abstracto y sin entidad suficiente para merecer tutela penal. Por ello es que el delito de negociaciones incompatibles se considera también un delito de peligro abstracto en relación con el patrimonio público, pues se pretende evitar que el funcionario obtenga ganancias ilícitas con su comportamiento y que perjudique patrimonialmente a la entidad pública respectiva. Pero, en este sentido, constituye un tipo de dudosa legitimidad: no es más que una forma de castigar criminalmente la mera sospecha de que se ha producido o se producirá una malversación o un fraude $e^{48}$. En consecuencia, teniendo en cuenta las consideraciones político-criminales efectuadas $y$, también, la elevada penalidad con que se sancionan estas conductas - al menos al cotejarla con la que se establece en el supuesto de prevaricación - parece del todo necesario restringir el ámbito de ejercicio de influencias vinculado a este delito, y excluir del tipo los supuestos en que la decisión que se pretende obtener de otro funcionario es adecuada o justa. De todos modos, el funcionario que ha ejercido indebidamente sus influencias será siempre sancionable en el ámbito administrativo.

Por su parte, en el evento de que un funcionario ejerza sus influencias sobre otro en virtud de un cohecho, es indudable que existe un importante desvalor de acción en la conducta de ese funcionario corrompido, aun cuando la decisión que se pretende obtener sea adecuada a Derecho. Es algo similar a lo que ocurre cuando se produce un cohecho para la realización de un acto propio del cargo, pero que no es contratio al ordenamiento jurídico (cohecho impropio). En realidad, el supuesto que nos ocupa corresponde más bien a un cohecho propio - modalidad agravada respecto del cohecho impropio- porque el sólo hecho de ejercer indebidamente una influencia ya constituye una infracción a los deberes del funcionario. Pero no se advierte razón alguna para que esa infracción sirva, al mismo tiempo, para calificar el cohecho como propio y para aumentar la pena según lo dispuesto en el inciso $2^{\circ}$

\footnotetext{
${ }^{47}$ En el delito de negociaciones incompatibles existe un peligro para el prestigio de los entes públicos, que se produce por el incumplimiento de las reglas de incompatibilidad de actividades privadas y públicas de los funcionarios públicos, cfr.

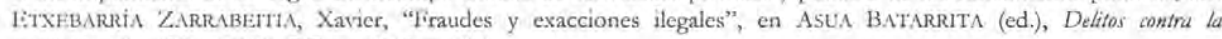
administnación piblica, IVAP, Bilbao, 1997, p. 206.

48

Cfr. CURY, Einrique, "Contribución politico-criminal al estudio de los delitos funcionarios", en Retista Chilena de Derecho, 1986. pp, 300-301 y LABATUT GLeNA, Gustavo, Derecho penal II, $7^{2}$ ed., reimpr. 2000, p. 84.
} 
del art. 248 bis, cuando a la postre el resultado que se pretende obtener es una decisión administrativa ajustada a Derecho. En suma, ese comportamiento queda incluido en el supuesto de cohecho propio, y no se aprecia un mayor desvalor que legitime una mayor pena.

\section{CONCLUSIONES}

El estudio de los delitos de tráfico de influencias nos ha conducido a cuestionar el merecimiento y necesidad de pena que esas conductas exhiben, unido a las enormes dificultades que existen para formular tipos delimitados y respetuosos de las exigencias del principio de legalidad. Desde este punto de vista, la fórmula adoptada en nuestro Código penal para hacer frente a algunos de estos comportamientos, vinculándolos con los delitos de negociaciones incompatibles y cohecho, resulta preferible a la regulación autónoma e indeterminada a la que se ha recurrido en otras legislaciones.

Pese a lo anterior, las disposiciones examinadas tampoco gozan de toda la precisión que se podía esperar. Admiten interpretaciones diversas, entre las cuales me he decantado por una postura especialmente restrictiva.

En primer lugar, en cuanto al modo de ejercer la influencia sobre otro empleado público, entiendo que ella sólo puede llegar a configurar estos delitos específicos cuando se realiza con prevalimiento o abuso de la función, de la relación jerárquica o de la relación personal que vincula a los dos funcionarios. Es decir, ha de tratarse del abuso de una situación de predominio, por la que se incide indebidamente en el proceso motivador que conduce al empleado habilitado a adoptar su decisión.

En segundo término, estimo que deben dejarse fuera del ámbito típico de estas figuras, los supuestos en que el ejercicio de influencias se realiza con el objeto de provocar una decisión justa o adecuada a Derecho, pues entonces no resultaría afectado el bien jurídico, o al menos no en una entidad suficiente para aplicar penas como las que prevé el art. 240 bis y 248 bis inc. $2^{\circ}$. En todo caso, tampoco se requiere que la resolución que se adopte sea constitutiva de un delito de prevaricación, sino que basta con que se aparte de la legalidad. Todo ello, teniendo en cuenta que ninguna de estas normas requiere que la decisión en cuestión llegue a adoptarse efectivamente.

Como se advierte, la literalidad de estos tipos no hace ninguna distinción como las que he propuesto. Una interpretación más o menos estricta depende, en gran medida, de la opción valorativa que se adopte al enjuiciar estas conductas. Ello puede verse especialmente condicionado por la particular repulsión y especial sensibilidad que existen en la actualidad frente a esta clase de comportamientos, que conduce a un deseo de sancionarlas penalmente y con el máximo rigor posible. 
Desde el punto de vista aquí asumido, por tanto, resulta criticable que restricciones como las propuestas no operen desde la propia literalidad del tipo. En ese sentido, además, las vaguedades terminológicas constatadas atentan contra la seguridad jurídica pues, aunque es admisible interpretar restrictivamente las figuras en virtud de los principios de fragmentariedad y ultima ratio, siempre es posible que un juez las interprete de otro modo sin tergiversar el texto de la ley. En definitiva, la redacción de estas normas es criticable porque permite subsumir hechos que carecen del desvalor propio del delito que se tipifica.

Por otra parte, la aplicación efectiva de estas normas ya es, de por sí, difícil. Y ciertamente, como afirma GARCÍ ARÁN, «la mejor manera de que un tipo penal no se aplique nunca es pretender que resulta aplicable a casi todon ${ }^{49}$. Por lo tanto, restringir el ámbito típico permite distinguir mejor según la gravedad de las conductas realizadas, lo que a la postre facilita la aplicación efectiva de la norma. Asi se evita que las normas penales no constituyan más que una reacción meramente simbólica frente a estos problemas.

No se puede olvidar que la prevención de comportamientos de corrupción y el saneamiento de la Administración demanda actuaciones firmes que están fuera del campo del Derecho penal. Este último puede colaborar al mejor funcionamiento de la Administración y protegerla de quienes pretenden enriquecerse a costa del interés general, pero sólo en la medida de sus posibilidades, respetando principios básicos como el de la proporcionalidad y subsidariedad.

\section{BIBLIOGRAFÍA}

AlONSO PÉREZ, Francisco, Delitos cometidos por los funcionarios públicos en el nuevo Código penal, Dykinson, Madrid, 2000.

BERDUGO GÓMEZ DE LA TORRE, Ignacio, "Anotaciones sobre el delito de tráfico de influencias", en ORTS BERENGUER (dir.), Delitos de los funcionarios públicos, Consejo General del Poder Judicial, Madrid, 1994, pp. 201-209

CATAL,Án SENDER, Jesús, Los delitos cometidos por autoridades y funcionarios públicos en el nuevo Código penal (doctrina y jurisprudencia), Bayer hnos. S.A., Barcelona, 1999.

Cugat MAuri, Miriam, La desviación del interés general y el tráfico de influencias, Cedecs, Barcelona, 1997

CURY, Enrique, "Contribución político-criminal al estudio de los delitos funcionarios", en Revista Chilena de Derecho, 1986, pp. 300-301.

Dínz Y Garcí CONLLIEDO, Miguel, "El delito de tráfico de influencias", en Asua Batarrita (ed.), Delitos contra la Administración Pública, IVAP, Bilbao, 1997, pp. 171-178.

\footnotetext{
Garcia Arin, op. cit. (n, 6), p. 103.
} 
EtXebARRíA ZarrabeitTA, Xavier, "Fraudes y exacciones ilegales", en ASUA BATARrita (ed.), Delitos contra la administración pública, IVAP, Bilbao, 1997, p. 204-232.

GARCía ARÃN, Mercedes, "Los delitos de tráfico de influencias en el Código penal de 1995", en MUÑOZ CONDE (dir.), Los delitos contra la Administración Pública en el nuevo Código penal, Instituto Andaluz de Administración Pública, Sevilla, 1997, pp. 81-103.

LABATUT GLENA, Gustavo, Derecho penal II, $7^{a}$ ed., reimpr. 2000.

Mexía García, Pablo, Los Conflictos de Intereses y la Corrupción Contemporánea, Aranzadi, Elcano (Navarra), 2001.

Mir Puig, Carlos, Los delitos contra la Administración Pública en el nuevo Código Penal, J.M. Bosch editor, Barcelona, 2000.

MORAles Prats/Rodríguez Puerta, "Del tráfico de influencias", en Quintero Olivares (dir.), Comentarios a la Parte Especial del Derecho penal, $2^{\mathrm{a}}$ ed., Aranzadi, Pamplona, 1999.

Morillas Cueva/Portilla CONTreras, "Los delitos de revelación de secretos, uso de información privilegiada, cohecho impropio y tráfico de influencias", en COBO DEL ROSAL (dir.), Comentarios a la Legislación penal, XVI, EDR, Madrid, 1994, pp. 173-244.

MUÑOZ CONDE, Francisco, "Los nuevos delitos de tráfico de influencias, revelación de secretos e informaciones y uso indebido de información privilegiada", Apéndice a Derecho Penal. Parte Especial, 8. ${ }^{2}$ ed., Tirant lo Blanch, Valencia, 1991.

MuÑoz CONDF, Francisco, Derecho penal. Parte especial, $13^{a}$ ed., Tirant lo Blanch, Valencia, 2001.

Silva Sínchez, Jesús María, La expansión del Derecho penal, $2^{a}$ ed., Civitas, Madrid, 2001.

SuÁrez MONTES, Rodrigo, "Consideraciones político-criminales sobre el delito de tráfico de influencias", en Politica Criminal y Reforma Penal. Homenaje a la memoria del Prof. Dr. D. Juan del Rosal, EDR, Madrid, 1993, pp. 1087-1106. 